\title{
The Transcriptional Response of Caenorhabditis elegans to Ivermectin Exposure Identifies Novel Genes Involved in the Response to Reduced Food Intake
}

\author{
Steven T. Laing ${ }^{1}$, Al Ivens ${ }^{2}$, Victoria Butler ${ }^{3}$, Sai P. Ravikumar ${ }^{3}$, Roz Laing ${ }^{1}$, Debra J. Woods ${ }^{4}$, John S. \\ Gilleard $^{3 *}$
}

1 Faculty of Veterinary Medicine, University of Glasgow, Glasgow, Strathclyde, United Kingdom, 2 Fios Genomics Ltd, The Edinburgh Technology Transfer Centre, Edinburgh, Lothian, United Kingdom, 3 Faculty of Veterinary Medicine, University of Calgary, Calgary, Alberta, Canada, 4 Research and Development, Pfizer Animal Health, Kalamazoo, Michigan, United States of America

\begin{abstract}
We have examined the transcriptional response of Caenorhabditis elegans following exposure to the anthelmintic drug ivermectin (IVM) using whole genome microarrays and real-time QPCR. Our original aim was to identify candidate molecules involved in IVM metabolism and/or excretion. For this reason the IVM tolerant strain, DA1316, was used to minimise transcriptomic changes related to the phenotype of drug exposure. However, unlike equivalent work with benzimidazole drugs, very few of the induced genes were members of xenobiotic metabolising enzyme families. Instead, the transcriptional response was dominated by genes associated with fat mobilization and fatty acid metabolism including catalase, esterase, and fatty acid CoA synthetase genes. This is consistent with the reduction in pharyngeal pumping, and consequential reduction in food intake, upon exposure of DA1316 worms to IVM. Genes with the highest fold change in response to IVM exposure, cyp-37B1, $m t l-1$ and $s c l-2$, were comparably up-regulated in response to short-term food withdrawal ( $4 \mathrm{hr}$ ) independent of IVM exposure, and GFP reporter constructs confirm their expression in tissues associated with fat storage (intestine and hypodermis). These experiments have serendipitously identified novel genes involved in an early response of $C$. elegans to reduced food intake and may provide insight into similar processes in higher organisms.
\end{abstract}

Citation: Laing ST, Ivens A, Butler V, Ravikumar SP, Laing R, et al. (2012) The Transcriptional Response of Caenorhabditis elegans to Ivermectin Exposure Identifies Novel Genes Involved in the Response to Reduced Food Intake. PLoS ONE 7(2): e31367. doi:10.1371/journal.pone.0031367

Editor: Clotilde K. Carlow, New England Biolabs, United States of America

Received November 6, 2011; Accepted January 9, 2012; Published February 14, 2012

Copyright: (c) 2012 Laing et al. This is an open-access article distributed under the terms of the Creative Commons Attribution License, which permits unrestricted use, distribution, and reproduction in any medium, provided the original author and source are credited.

Funding: Dr. Steven Laing was supported by a Biotechnology and Biological Sciences Research Council CASE Studentship and the Biosciences Knowledge Transfer Network (formerly Genesis Faraday). The funders had no role in study design, data collection and analysis, decision to publish, or preparation of the manuscript. Additional funding was supplied by Pfizer PIc. Dr. Deborah Woods, who is employed by Pfizer, provided advice and support regarding the use of the HPLC-MS, so she had technical and intellectual input into that aspect.

Competing Interests: The authors have read the journal's policy and have the following conflicts: One author (Al Ivens) is employed by Fios Genomics Ltd and another (Deborah Woods) is employed by Prizer Animal Health. In addition, the study received some funding support from Pfizer Animal Health PLC. This does not alter the authors' adherence to all the PLoS ONE policies on sharing data and materials.

*E-mail: jsgillea@ucalgary.ca

\section{Introduction}

The macrocyclic lactone ivermectin (IVM) is one of the most important drugs used for the control of animal and human parasites [1,2]. It has been the mainstay of livestock parasite control since the early $1980 \mathrm{~s}$, but intensive use has led to the widespread development of drug resistance [2-5]. Over the last decade IVM has been increasingly used in community-wide treatment programs, aimed at the eradication of a number of human filarial parasite species. Resistance appears now to be emerging as a consequence of this intensive drug selection pressure [6-8]. In order to maintain IVM efficacy in regions where resistance has not arisen, and to aid in the development of novel synergists, it is essential that the mechanism of action of the drug and the molecular mechanisms employed by parasites that result in resistance are elucidated.

Genetic, molecular and electrophysiological studies on the freeliving nematode Caenorhabditis elegans have been central to identifying the major direct molecular targets of IVM [9-13]. It acts by irreversibly binding to, and activating, ligand-gated ion channels, particularly glutamate-gated chloride channels (GluCls), resulting in paralysis of the body wall and pharyngeal muscles [1416]. This in turn leads to generalized paralysis and decreased feeding. A number of comparative studies suggest that IVM acts in a similar way in parasitic nematodes [15-17].

The ultimate effect of a drug on an organism is a balance between the immediate effects of drug-receptor interaction; secondary and compensatory responses to these interactions (pharmacodynamics); and the effect of the organism on the drug (pharmacokinetics). As discussed above, the immediate effect of IVM-receptor interaction has been studied intensively, and is known to cause pharyngeal and body wall paralysis. However, the biological response of the nematode to this phenotype, and potential compensatory mechanisms induced following drug exposure, have received little attention. We have previously shown that exposure of $C$. elegans to the benzimidazole drug albendazole induces an array of xenobiotic metabolizing enzymes [18]. The transcriptomic response of nematodes to IVM exposure, a highly lipophilic drug that undergoes minimal metabolism in mammals, has not previously been described [19]. 
Wild-type C. elegans exposed to even low doses of ivermectin are rapidly paralysed leading to death. In order to minimise nonspecific, stress-related changes in the transcriptome following drug exposure, we made use of the strain DA1316, which has a null mutation in three subunits of the glutamate-gated chloride channel target of IVM. Although this strain is largely resistant to the paralytic effects of IVM on the body wall, we found that following four hours exposure to high doses of the drug there is a significant decrease in pharyngeal function. As a result many of the differences in gene expression noted between the IVM exposed and unexposed groups are due to chemically induced reduced food intake of the exposed nematodes.

As well as being accepted as a model for many features of parasitic nematode biology, C. elegans is increasingly used as a model for the basic biology of satiety and obesity [20,21]. There have been many studies investigating the transcriptomic response of C. elegans to starvation, in particular that of the long-lived, anorexic dauer stage $[22,23]$. However, thus far investigation of short-term food deprivation has been limited to real-time PCR based studies of genes expected to be involved in this response [24]. To the authors' knowledge this is the first unbiased, wholegenome investigation of the immediate effects of food deprivation in C. elegans and in any whole organism.

\section{Materials and Methods}

\section{C. elegans strains and maintenance}

Strain DA1316 (avr-14(ad1302); avr-15(vu227); glc-1(pk54)) was used in all experiments. This strain is a triple mutant of the glutamate-gated chloride channel subunits avr-14, avr-15 and $g l c-1$, conferring high-level resistance to IVM (pers. Comm., Dr. J. Dent). The wild-type strain used in pharyngeal pumping assays was the Bristol N2 strain. Both strains were gifts from the Caenorhabditis Genetics Center (CGC).

\section{Synchronisation of cultures}

Embryos were isolated by hypochlorite treatment of gravid adults [25]. The embryos were transferred to a $5 \mathrm{~cm}$ diameter Petri dish in $6 \mathrm{ml}$ of S-buffer $\left(129 \mathrm{ml} / \mathrm{L} \quad 0.05 \mathrm{M} \mathrm{K}_{2} \mathrm{HPO}_{4}\right.$, $871 \mathrm{ml} / \mathrm{L} 0.05 \mathrm{M} \mathrm{KH}_{2} \mathrm{PO}_{4}, 0.1 \mathrm{M} \mathrm{NaCl} ; \mathrm{pH} 6.0$ ), and maintained at $20^{\circ} \mathrm{C}$ overnight. The concentration of $\mathrm{L} 1$ larvae was calculated the following day and experimental cultures initiated immediately.

\section{Pharyngeal pumping assay}

IVM (Sigma, Gillingham, Dorset, UK) plates were prepared to final concentrations of $0,1,10,100$ and $1000 \mathrm{ng} / \mathrm{ml}(0,1.1 \mathrm{nM}$, $11.4 \mathrm{nM}, 0.1 \mu \mathrm{M}, 1.1 \mu \mathrm{M}$ ) IVM. Dimethyl sulphoxide (DMSO) was used to dissolve the IVM and was present in all plates at a final concentration of $0.01 \% \mathrm{v} / \mathrm{v}$. Synchronised N2 and DA1316 L1 larvae were allowed to grow on standard nematode growth medium (NGM) plates at $20^{\circ} \mathrm{C}$ for $53 \mathrm{hr}$. The L4/young adults were then picked on to drug plates and allowed to remain at $20^{\circ} \mathrm{C}$ for a further $4 \mathrm{hr}$. The number of pharyngeal pumps was counted over a period of $1 \mathrm{~min}$ for five worms of each strain at each concentration of drug.

\section{Anthelmintic exposures}

Ten thousand DA1316 L1 larvae per experimental condition were grown for $53 \mathrm{hr}$ at $20^{\circ} \mathrm{C}$ on standard NGM plates with OP50 bacterial lawns. The nematodes were assessed for comparable staging between groups then washed from the plates with M9 buffer into a $50 \mathrm{ml}$ falcon tube and washed twice in M9 buffer. The suspension of worms was split equally between control plates
(DMSO $0.001 \%$ and $0.01 \% \mathrm{v} / \mathrm{v}$ for $100 \mathrm{ng} / \mathrm{ml}(0.1 \mu \mathrm{M})$ and $1 \mu \mathrm{g} / \mathrm{ml}(1.1 \mu \mathrm{M})$ IVM experiments respectively) and plates containing $100 \mathrm{ng} / \mathrm{ml}(0.1 \mu \mathrm{M})$ or $1 \mu \mathrm{g} / \mathrm{ml}(1.1 \mu \mathrm{M})$ IVM (Sigma, Gillingham, Dorset, UK) at a density of 500-600 worms per $5 \mathrm{~cm}$ diameter plate. Drug and control plates were made and seeded with $100 \mu \mathrm{l}$ OP50 suspension 16-24 hr prior to the introduction of the larvae. After $4 \mathrm{hr}$ exposure the nematodes were washed from the drug plates with M9 buffer, washed twice in M9 and the pellet of worms snap frozen and stored in liquid nitrogen until RNA extraction.

\section{Real-time QPCR biological replicates}

Separate biological replicates were carried out for analysis by real-time QPCR (RTPCR) in an identical manner to the microarray experiments except for the use of a commercial preparation of IVM (Virbamec $5 \mathrm{mg} / \mathrm{ml}$ IVM, Virbac, Bury St. Edmunds, Suffolk, UK). In order to compare the transcriptomic response to IVM exposure and short-term food deprivation, nematodes were first grown as per the acute drug exposure protocol and then transferred either to plates containing IVM, control plates or control plates with no OP50 food source for $4 \mathrm{hr}$ before harvesting. Investigation of gene up-regulation following exposure to a gradient of IVM concentrations was undertaken. Five matched cultures of $C$. elegans were grown in standard liquid culture medium for $70 \mathrm{hr}$ at $20^{\circ} \mathrm{C}, 200 \mathrm{rpm}$. Cultures were exposed to $0,1,10,100,1000 \mathrm{ng} / \mathrm{ml}(0,1.1 \mathrm{nM}, 11.4 \mathrm{nM}$, $0.1 \mu \mathrm{M}, 1.1 \mu \mathrm{M}) \mathrm{IVM}$ for $4 \mathrm{hr}$, harvested by sucrose flotation and snap frozen in liquid nitrogen [26].

\section{RNA methods}

RNA extractions were carried out using Trizol Reagent (Invitrogen, Paisley, UK), according to the manufacturer's instructions. Harvested C. elegans were homogenised in four volumes Trizol reagent, subject to two chloroform extractions and precipitated in isopropanol. The RNA was then treated with RNase-free DNase I (Qiagen, Crawley, West Sussex, UK) in solution before purification and concentration using RNeasy columns (Qiagen, Crawley, West Sussex, UK). Quality and concentration of RNA was assessed using an Agilent Bioanalyser 2100. Total RNA destined for microarray analysis was reprecipitated in ethanol. RNA for real-time QPCR analysis was reverse transcribed using a cloned AMV first strand synthesis kit (Invitrogen, Paisley, UK) and random hexamer primers. $5 \mu \mathrm{g}$ total RNA for each sample was used as template and an identical reaction lacking reverse transcriptase enzyme was carried out simultaneously as a negative control. cDNA was purified using PCR purification columns (Qiagen, Crawley, West Sussex, UK), resuspended in $30 \mu \mathrm{l} \mathrm{TE}$ buffer and stored at $-80^{\circ} \mathrm{C}$ until use.

\section{Microarray hybridisation and analysis}

Sample labelling and hybridisation to C. elegans whole genome Genechips (Affymetrix, High Wycombe, UK) were performed using standard Affymetrix protocols (http://media.affymetrix. com/support/downloads/manuals/expression_analysis_technical_manual.pdf). These chips contain oligonucleotide probesets designed to assess over 22500 transcripts from the C. elegans genome. An updated annotation dataset was assembled for the $C$. elegans probesets present on the Genechip. Data were sourced from WormBase (Sept. 2008). Scanned array images (CEL files) were quality control assessed using the arrayQualityMetrics Bioconductor package (www.bioconductor.org) in the $\mathrm{R}$ environment (www.r-project.org). Arrays identified as possible outliers were removed from subsequent analyses. Linear model fitting of the array data was undertaken, taking into account biological 
replicates using the limma (Linear Models for Microarray Data) Bioconductor package (www.bioconductor.org/packages/bioc/ html/limma.html). The Rank Products algorithm was used to assess differential expression of genes between test and control groups and to assign significance to these changes [27]. Assignment of significance was carried out using a False Discovery Rate (FDR) cut-off of 5-10\%.

\section{Gene Ontology analysis}

DAVID software (the Database for Annotation, Visualisation and Integrated Discovery) from the National Institutes of Health was used to assess the functional annotation and clustering of the differentially expressed genes [28,29]. Input into the program consisted of probesets shown to be significantly altered in expression using the Rank Products algorithm, with a false discovery rate (FDR) of less than $10 \%$. Prevalence of annotation terms within the list of differentially expressed genes was compared to the prevalence in the whole C. elegans genome. Fold enrichment was calculated and a modified Fishers exact test (EASE score) used to assign significance. Gene functional classification clustering was carried out using medium stringency (DAVID).

\section{Real-time Quantitative PCR}

Relative quantitation of genes of interest was assessed using Brilliant SYBR Green QPCR master mix (Agilent [Stratagene], Stockport, Cheshire, UK) and a Stratagene Mx 300P QPGR system with Stratagene MxPro software. ama-1, encoding a subunit of RNA polymerase II, was used as a normalising gene. This constitutively expressed gene showed no significant changes on microarray analysis and has been extensively used as a normalising gene in differential expression studies in C. elegans [30]. Gene specific primers were designed to produce a product between 160 and $200 \mathrm{bp}$ in length. The sequences of these primers can be found in Table S1. The final concentration of primers was between $300 \mathrm{nM}$ and $400 \mathrm{nM}$ in a total reaction volume of $25 \mu \mathrm{l}$.

\section{Expression pattern analysis}

GFP reporter constructs for $m t l-1$, scl-2, C23G10.11, cyp-37B1, and ilys-3 were created using a PCR fusion protocol [31]. The putative promoter region, $3 \mathrm{~Kb}$ upstream from the ATG start site of the gene of interest, was fused to the $g f p$ gene, including synthetic introns and unc-54 3' UTR, from Fire vector pPD95.67 [32]. The plasmid used contained a $g f p$ gene with a nuclear localisation signal. Primer sequences can be found in Table S1. Transgenic lines were created using the method of Mello et al., with the plasmid pRF-4 as a co-transformation marker to identify transgenic worms [33]. Expression patterns were visualised using a Zeiss, Axioscop 2 plus microscope. Images were collected and processed using Improvision Openlab software (www.improvision. com).

\section{Results}

\section{Pharyngeal pumping rate of DA1316 is reduced following exposure to IVM}

Strain DA1316 is highly resistant to the effects of IVM on motility. Although wild-type worms (N2) exposed to $100 \mathrm{ng} / \mathrm{ml}$ $(0.1 \mu \mathrm{M})$ IVM for as little as one hour exhibited a dramatic paralysis phenotype, exposure of strain DA1316 to the same concentration of drug for up to $6 \mathrm{hr}$ had no visible effect on motility, as has been previously described (data not shown). In contrast, although the strain is resistant to the effects of IVM on the pharynx relative to wild type worms, we found that four hours exposure of DA1316 to IVM results in a significant decrease in pharyngeal activity (Figure 1). The number of pharyngeal pumps per minute is reduced by $50 \%$ following exposure to $100 \mathrm{ng} / \mathrm{ml}$ $(0.1 \mu \mathrm{M})$ IVM. The drug is thought to elicit its effect on the pharynx via the AVR-15 subunit in pharyngeal GluCls [9,12]. However, avr-15 (vu227), presumed to be a null mutation of avr-15, does not appear to confer complete resistance to the effect of IVM on the C. elegans pharynx.

Acute exposure of DA1316 to $0.1 \mu \mathrm{M}$ and $1.1 \mu \mathrm{M}$ IVM results in differential expression of a distinct set of genes that may be involved in the response to food deprivation

Microarray analysis was performed on RNA from five biological replicates of strain DA1316 exposed to $100 \mathrm{ng} / \mathrm{ml}(0.1 \mu \mathrm{M}) \mathrm{IVM}$. Twelve probesets were considered to be significantly up-regulated and three considered to be significantly down-regulated $(\mathrm{FDR}<5 \%)$. The top 10 up-regulated genes, based on $\log _{2}$ fold change, are listed in Table 1. Many of the up-regulated genes are uncharacterised, but those with known or putative functions may have roles in fat metabolism. Given the low number of genes showing significant changes in expression the experiment was repeated using $1 \mu \mathrm{g} / \mathrm{ml}(1.1 \mu \mathrm{M})$ IVM in a similar manner. Again five drug-exposed and five matched controls underwent analysis. The rank products algorithm revealed 369 probesets to be significantly altered in expression with a FDR correction to $5 \%$ (216 up-regulated and 153 down-regulated). Figure 2 summarises the microarray data and Table 2 lists the top 10 up-regulated and down-regulated probesets based on $\log _{2}$ fold change. Full microarray data is available in Table $\mathbf{S 2}$ and online at the GEO website, accession number GSE22660. Many genes are represented in the top up-regulated and down regulated lists for both the $0.1 \mu \mathrm{M}$ and $1.1 \mu \mathrm{M}$ experiments, including the presence of $m t l-1, s c l-2$ and $c y p-37 B 1$ in the top four up-regulated genes, which suggests there is a consistent response at the two doses of drug.

Genes that showed significant changes in expression level following exposure of strain DA1316 to $1 \mu \mathrm{g} / \mathrm{ml}(1.1 \mu \mathrm{M}) \mathrm{IVM}$ $(\mathrm{FDR}<10 \%)$ were subject to ontology analysis. A less stringent FDR cut-off was used to widen the scope of the analysis and included 254 up-regulated and 186 down-regulated genes. The gene ontology terms associated with a minimum of two genes and with an associated EASE score ( $p$-value) of $\leq 0.1$, for both data sets, are described (Table S3 and S4). Only 72 up-regulated and 94 down-regulated genes were associated with significantly enriched ontology terms. This is likely due to the large number of completely uncharacterised genes in both sub-categories.

Up-regulated terms include oxidoreductase activity, generation of precursor metabolites and energy; metabolic process; organic acid metabolic process; carboxylic acid metabolic process and catabolic process. These terms are associated with several genes which may be important in fatty acid synthesis, breakdown and metabolism including five cytochrome P450 genes, two flavin containing monooxygenases (FMO) and three catalase genes; two short chain dehydrogenase genes and an alcohol dehydrogenase gene; a fatty acid desaturase gene and a gamma butyrobetaine hydroxylase (potentially involved in carnitine biosynthesis). The most significantly enriched biological process ontology term is aging, which includes $m t l-1$, sodh1, cyp-34A9 and dod-3. In addition, this group contains other downstream targets of DAF-16, the sole C. elegans forkhead Box O transcription factor homologue and a mediator of insulin signalling $[21,34]$. These include catalase genes $(c t l-2, c t l-1)$; a gut esterase (ges-1); a fatty acid CoA synthetase gene (acs-17); a predicted isocitrate lyase/malate synthase (gei-7); and an acylsphingosine amidohydrolase (asah-1). All of these genes may be involved in fatty acid metabolism pathways. Furthermore, the only KEGG 


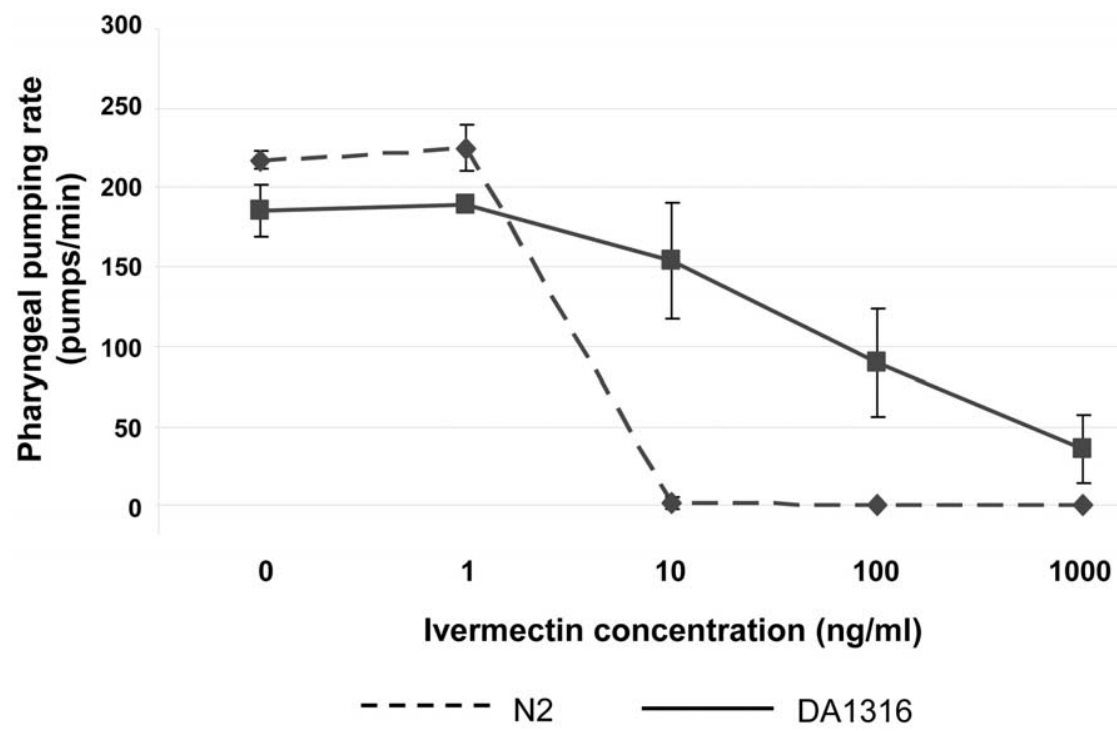

Figure 1. Pharyngeal pumping rate following $4 \mathrm{hr}$ exposure of DA1316 and $\mathbf{N 2}$ to $\mathbf{0 - 1 0 0 0 ~} \mathbf{n g} / \mathrm{ml}(\mathbf{1 . 1 4} \mu \mathrm{M})$ IVM. Whilst strain DA1316 is more resistant to IVM induced pharyngeal paralysis, at concentrations greater than $100 \mathrm{ng} / \mathrm{ml}(0.1 \mu \mathrm{M})$ the pharyngeal pumping rate is significantly reduced. The pharyngeal pumping rates of five worms were counted at each concentration of IVM and the error bars represent the standard deviation.

doi:10.1371/journal.pone.0031367.g001

pathway term to be significantly enriched in the up-regulated gene list was fatty acid metabolism. This was associated with five genes: F54F3.4, acs-2, sodh-1, acs-17 and F58F9.7.

The down-regulated gene-list is significantly enriched for the biological process term carboxylic acid metabolic process, which is associated with the fatty acid desaturase genes fat-5, fat- 6 and $f a t-7$; and several hypothetical proteins with acyl-CoA thioesterase, acylCoA dehydrogenase, acyl-CoA oxidase, glycine dehydrogenase KOGs. Additionally, the fatty acid elongase genes elo-2, elo-5 and elo-6; and genes involved in lipid transport, including the vitellogenins vit-1, vit-3 and vit-4, are down-regulated. Carbohydrate metabolic processes, exemplified by the UDP-glucuronosyl transferases ugt-12, ugt-46; the lysozyme genes lys-5 and lys-6; gale-1 (a putative UDP-galactose-4-epimerase) and ger-1 (a putative GDPketo-6-deoxymannose 3,5-epimerase/4-reductase) are also enriched in the down-regulated gene list. Further evidence that IVM exposure does not result in a classical xenobiotic response is seen by the significant down-regulation of the molecular function terms catalytic activity, oxidoreductase and transferase activity. These terms are associated with six UDP-glucuronosyl/glucosyl transferases, four glutathione-s-transferases, one cytochrome P450 and one short-chain dehydrogenase; all of which represent gene families that would be expected to be up-regulated in a xenobiotic detoxification response.

The transcriptomic response to IVM exposure is inconsistent with a general stress response: A panel of genes that have been associated with stress, such as hsp-70, gst-1, gst-38, sip-1 and HSF-1, show no significant change in expression in the microarray experiments; and others such as $h s p-16.1, h s p-16.49$ and $g s t-4$ are in fact significantly down-regulated in the current study (Table S5). Instead, the overall analysis suggests that the predominant response is associated with an increase in lipid catabolism. We hypothesised that this was likely to be a result of short-term food deprivation associated with the reduced pharyngeal pumping, and hence feeding, which occurs following exposure of the DA1316 strain to IVM. In order to investigate this hypothesis further we

Table 1. Top 10 up-regulated probesets based on fold change following $4 \mathrm{hr}$ exposure of DA1316 to $100 \mathrm{ng} / \mathrm{ml}(0.1 \mu \mathrm{M})$ IVM.

\begin{tabular}{|c|c|c|c|c|}
\hline Probeset & Gene ID & $\log _{2}$ FC & FDR & Ontology \\
\hline 172744_at & $m t l-1$ & 1.59 & 0 & metallothionein \\
\hline 184913_s_at & T22F3.11 & 1.44 & 0 & permease of major facilitator family KOG \\
\hline 192737_at & scl-2 & 1.31 & 0 & sterol carrier-like protein \\
\hline 189221_at & сур-37B1 & 1.27 & 0 & cytochrome P450 (CYP4/19/26 subfamilies) \\
\hline 186971_at & C23G10.11 & 1.23 & 0 & uncharacterised \\
\hline 173729_at & T22F3.11 & 1.21 & 0 & permease of major facilitator family KOG \\
\hline 183381_at & C50F7.5 & 1.12 & $1.00 \mathrm{E}-02$ & uncharacterised \\
\hline 186521_at & $\mathrm{F} 21 \mathrm{C} 10.10$ & 1.10 & $1.11 \mathrm{E}-02$ & uncharacterised \\
\hline 173550_at & F45D3.4 & 1.08 & $1.25 \mathrm{E}-02$ & uncharacterised \\
\hline 190978_at & sodh-1 & 1.07 & $1.82 \mathrm{E}-02$ & alcohol dehydrogenase class V KOG \\
\hline
\end{tabular}




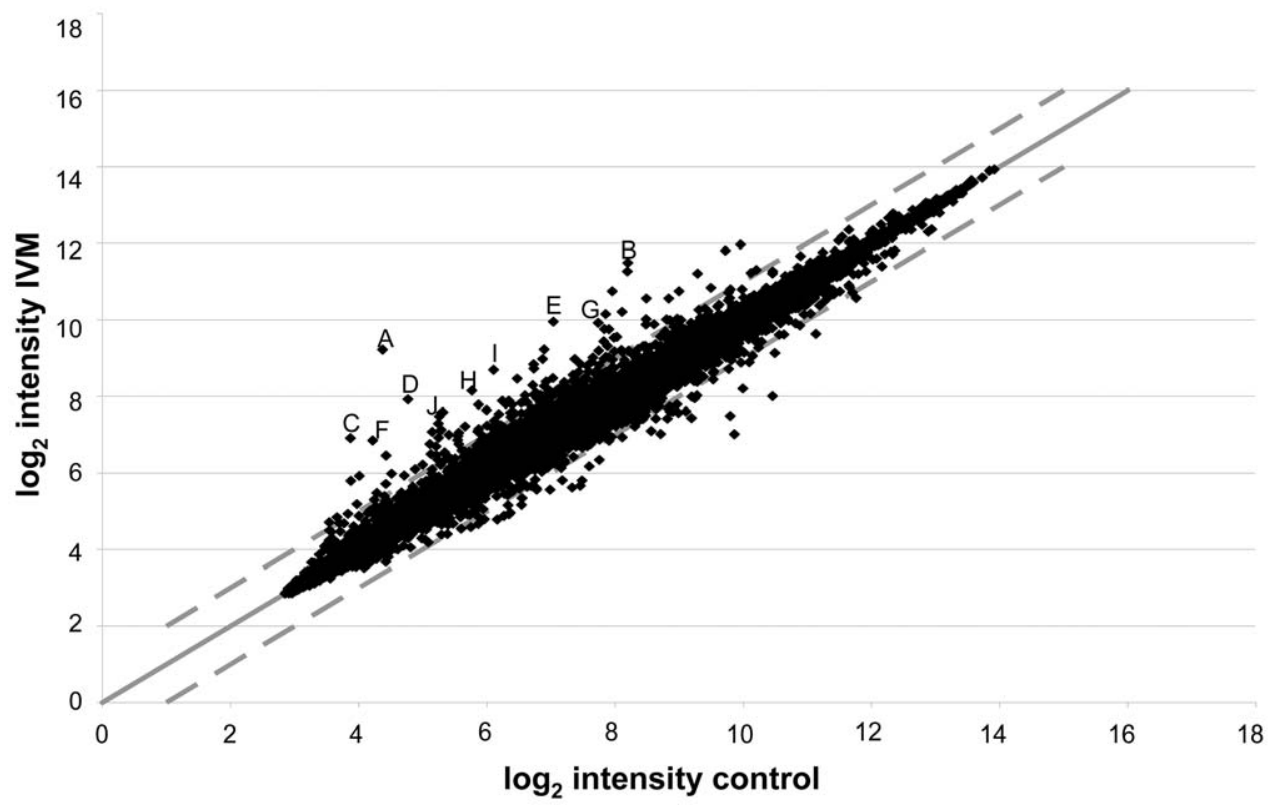

Figure 2. Model fitted $\log _{2}$ control chip intensity vs. $\log _{2}$ IVM $(1 \mu \mathbf{g} / \mathbf{m l}, 1.1 \mu M)$ chip intensity. The scatter plot represents the entire 22625 probesets represented on the Affymetrix chips. The upper and lower dashed lines represent up-regulation greater than 2-fold and downregulation greater than 2 -fold respectively. The data points marked $\mathrm{A}-\mathrm{H}$ represent the top 10 up-regulated genes in Table 2 .

doi:10.1371/journal.pone.0031367.g002

Table 2. Top 10 up-regulated and down-regulated genes based on fold change following $4 \mathrm{hr}$ exposure of DA1316 to $1 \mu \mathrm{g} / \mathrm{ml}$ $(1.1 \mu \mathrm{M})$ IVM.

\section{UP-REGULATED GENES}

\begin{tabular}{|c|c|c|c|c|}
\hline Probeset & Gene ID & $\log _{2} F C$ & FDR & Ontology \\
\hline 172744_at & $m t /-1$ & 4.99 & 0 & metallothionein \\
\hline 192737_at & scl-2 & 3.27 & 0 & sterol carrier-like protein \\
\hline 186971_at & C23G10.11 & 3.20 & 0 & uncharacterised \\
\hline 189221_at & сур-37B1 & 3.09 & 0 & cytochrome P450 (CYP4/19/26 subfamilies) \\
\hline 177613_at & F57G8.7 & 3.01 & 0 & uncharacterised \\
\hline 177671_at & K03D3.2 & 2.83 & 0 & uncharacterised \\
\hline 178900_s_at & F45D3.4 & 2.77 & 0 & uncharacterised \\
\hline 187964_at & F54F3.3 & 2.51 & 0 & triglyceride lipase-cholesterol esterase KOG \\
\hline 180946_at & ilys-3 & 2.51 & 0 & invertebrate lysozyme \\
\hline 173335_s_at & dod-3 & 2.33 & 0 & down stream of daf-16 \\
\hline \multicolumn{5}{|c|}{ DOWN-REGULATED GENES } \\
\hline 176939_at & spp-23 & -2.79 & 0 & saposin-like protein family \\
\hline 190404_s_at & folt-2 & -2.55 & 0 & putative folate transporter \\
\hline 179187_s_at & F46F2.3 & -2.36 & 0 & uncharacterised \\
\hline 189345_at & pho-13 & -1.88 & 0 & predicted intestinal acid phosphatase \\
\hline 192528_at & C35A5.3 & -1.83 & 0 & uncharacterised \\
\hline 187085_s_at & gst-10 & -1.77 & 0 & glutathione-s-transferase \\
\hline 190744_at & ugt-63 & -1.77 & 0 & UDP-glucuronosyl/glucosyl transferase KOG \\
\hline 175489_at & F18E3.11 & -1.72 & 0 & uncharacterised \\
\hline 177747_at & F58G6.9| srm-3 & -1.72 & 0 & uncharacterised \\
\hline 188441_at & F21F8.4 & -1.70 & 0 & KOG- aspartyl protease \\
\hline
\end{tabular}

doi:10.1371/journal.pone.0031367.t002 
compared our data to that of Van Gilst (2005) who identified 18 genes whose expression was significantly influenced by food withdrawal, using a quantitative real-time PCR screen of 97 candidate genes (Figure 3) [24]. The majority of the 18 genes identified by Van Gilst et al. as fasting response genes were similarly differentially expressed in microarray analysis of DA1316 exposed to IVM. This supports the hypothesis that the predominant response to IVM was secondary to its effect on the nematode pharynx. cpt-4 was the only gene whose regulation was discordant, being up-regulated in response to IVM exposure and down- regulated in response to fasting. However, this gene is thought to encode a carnitine palmitoyl transferase, which would be expected to be up-regulated with increased fat catabolism.

\section{Real-time QPCR confirmation of microarray data}

Genes which showed the greatest fold up-regulation following IVM exposure in the microarray experiments were further assessed using real- time QPCR. All of the genes examined that were proposed to be up-regulated by the microarray experiments were confirmed to be up-regulated by this technique (Figure 4). sip-1, gst-1 and HSF-1 are genes that have been associated general stress responses. These were included in the RT-QPCR analysis as negative controls and none showed any evidence of induction, supporting the earlier conclusion of a lack of a generalised stress response to IVM exposure. Expression of $c y p-35 C 1$, which we have shown to be upregulated in response to albendazole exposure, was unchanged following IVM exposure [27]. In addition, $p g p-1$, an example of the p- glycoproteins that have been advocated to be responsive to chronic IVM exposure, showed no change in expression [35].

cyp-37B1, mtl-1 and scl-2 represent novel genes involved in the response to food deprivation

$c y p-37 B 1, m t l-1$ and scl-2 were in the top four induced genes for both the $100 \mathrm{ng} / \mathrm{ml}(0.1 \mu \mathrm{M})$ and $1 \mu \mathrm{g} / \mathrm{ml}(1.1 \mu \mathrm{M})$ microarray experiments and their high level of induction was confirmed by RT-PCR. Additionally, both $c y p-37 B 1$ and $m t l-1$ have previously been shown to be responsive to exposure to other xenobiotics including clofibrate, $\beta$-naphthoflavone, PCB52, fluoranthene, progesterone and oestrogen [36-38]. Therefore, these genes were examined in more detail to characterize their response to both IVM exposure and food withdrawal.

First, the dose responsiveness of $c y p-37 B 1$, scl-2 and $m t l-1$ was examined to relate the effects to those seen on the pharyngeal paralysis phenotype (Figure 5A). All respond to IVM in a dose responsive manner, with significant changes occurring in gene expression at doses of IVM greater than $10 \mathrm{ng} / \mathrm{ml}(11.4 \mathrm{nM})$. This is consistent with the drug concentration at which IVM begins to affect the pharynx of DA1316 (Figure 1). The induction of expression of these three genes following nutritional deprivation (food removal) for $4 \mathrm{hr}$ was examined and all were found to be upregulated (Figure 5B). Furthermore, the level of induction was very similar to that produced by a $4 \mathrm{hr}$ exposure to $1 \mu \mathrm{g} / \mathrm{ml}$ $(1.1 \mu \mathrm{M})$ of IVM, a concentration that results in almost complete pharyngeal paralysis in DA1316. cyp-35C1, included as a negative

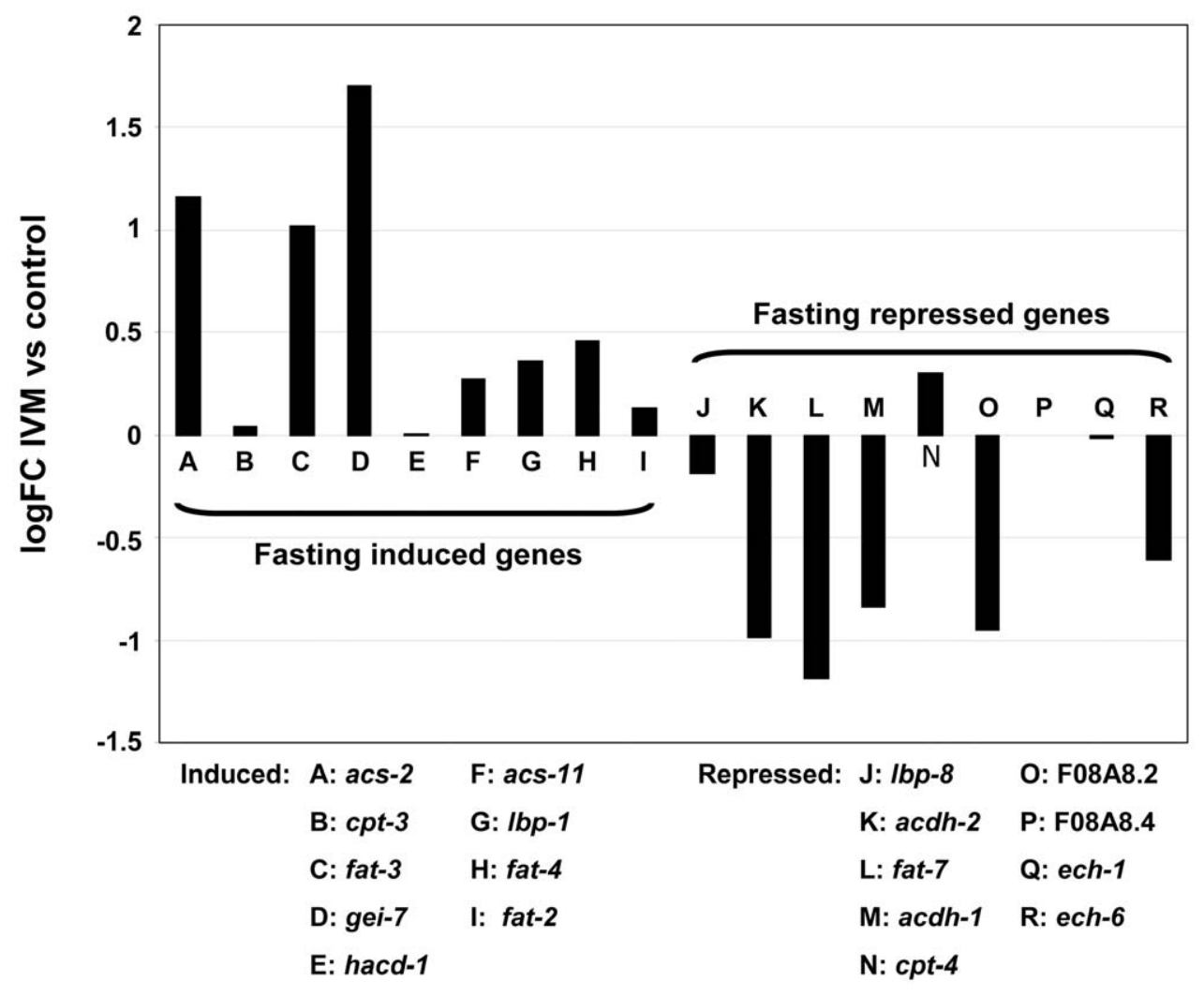

Figure 3. Differential expression of 18 fasting response genes*, in the $1 \mu \mathrm{g} / \mathrm{ml}(1.1 \mu \mathrm{M})$ IVM exposure microarray experiment. In general genes that were shown to be induced by fasting were also induced following exposure to IVM and fasting repressed genes were also repressed by IVM exposure. *Taken from van Gilst et al. 2005 [24].

doi:10.1371/journal.pone.0031367.g003 


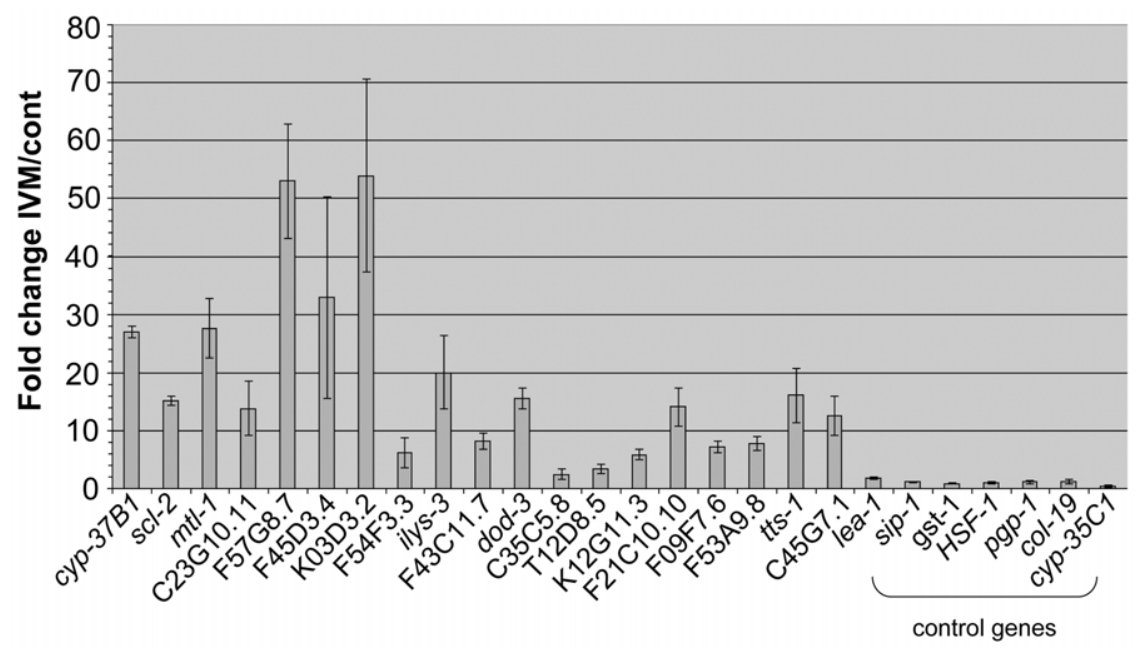

Gene of Interest

Figure 4. RTPCR assessment of gene expression following $\mathbf{4} \mathbf{~ h r}$ exposure to IVM. Strain DA1316 was exposed to $1 \mu \mathrm{g} / \mathrm{ml}$ [1.1 $\mu$ M] IVM (Virbamec) for $4 \mathrm{hr}$. Results are expressed as fold change relative to an unexposed control. Biological replicates were carried out in triplicate and the error bars represent the standard error. All genes proposed to be up-regulated by microarray were confirmed by RT-QPCR. doi:10.1371/journal.pone.0031367.g004

control, shows no change in either of the conditions examined in the current study.

\section{IVM responsive genes are predominantly expressed in} the intestine and hypodermis

The expression patterns of a number of the induced genes were investigated. GFP transgenes of $m t l-1, c y p-37 B 1$ and scl-2 and ilys-3 showed GFP expression in the intestinal cells (Figure 6), which is an important site for fat storage [39]. Additionally, $m t l-1$ showed expression in the terminal bulb of the pharynx (Figure 6), as has been reported previously [39,41]. In addition to the intestinal cells, the transcriptional reporter for $c y p-37 B 1$ showed expression in two cells in the tail region, which were assumed to be the phasmid neurons. These are proposed to be chemosensory neurons involved in avoidance of noxious chemical stimuli [42]. C23G10.11 was expressed in the hypodermal cells, which are also proposed to be a site of fat storage [43].

\section{Discussion}

The transcriptional response of C. elegans strain DA1316 exposed to IVM is dominated by genes associated with fat mobilization and fatty acid metabolism

The transcriptional response of the C. elegans strain DA1316 (avr14(ad1302); avr-15(vu227); glc-1(pk54)) to IVM appears to be dominated by genes associated with the consequences of food deprivation, such as changes to fatty acid metabolism, many of which are conserved in higher mammals. Comparative analysis of our results with those of Van Gilst et al. (2005), provide compelling evidence for this (Figure 3) [24]. Furthermore we have directly demonstrated that the three genes most consistently induced by IVM exposure in our experiments ( $m t l-1, c y p-37 B 1$ and $s c l-2)$ are in fact directly inducible by food withdrawal in the absence of the drug. This conclusion is supported by the phenotype of the DA1316 strain when exposed to IVM. Although this strain, which has null mutations in three glutamate-gate chloride channels (avr14 , avr-15 and $g l c-1$ ), is highly resistant to the paralytic effects of the drug on body wall muscle, we found it was still sensitive (albeit less than wild type) to IVM induced pharyngeal paralysis (Figure 1).
At doses of IVM of $100 \mathrm{ng} / \mathrm{ml}(0.1 \mu \mathrm{M})$ reduced pharyngeal pumping was evident with almost complete paralysis at $1 \mu \mathrm{g} / \mathrm{ml}$ $(1.1 \mu \mathrm{M})$ (Figure 1). Hence the major effect of IVM on the DA1316 worms is likely to be a reduction in food intake. It should be noted that, in contrast, Ardelli et al. (2009) reported that an avr14 , avr-15 and glc-1 triple mutant showed no reduction in pharyngeal activity following $2.5 \mathrm{hr}$ exposure to IVM at concentrations of up to $5 \mu \mathrm{M}$ [44]. It may be that the longer period of exposure, $4 \mathrm{hr}$ in the current study compared to $2.5 \mathrm{hr}$ in that of Ardelli et al., explains these differences.

We did not specifically investigate the effects of IVM-induced reduction of pharyngeal pumping rate on worm development and growth. However, it is interesting to note that DA1316 larvae grown on NGM containing IVM took longer to reach adulthood compared with those grown on drug-free plates; even at IVM doses as low as $11.4 \mathrm{nM}$ (data not shown). At present, the extent to which the transcriptional response described here leads to metabolic changes that functionally compensate for reduced feed intake is not clear, and this will be an interesting area of future investigation.

These results also provide an interesting example of the care that needs to be taken when interpreting the transcriptional responses to drug exposure. At first sight some of the induced genes could be interpreted as being part of a specific xenobiotic response to IVM exposure, and perhaps represent candidate enzymes that may metabolize the drug. The cytochrome $\mathrm{P} 450$ gene $c y p-37 B 1$ might be taken to be such a candidate. However, cytochromes $\mathrm{P} 450$ have roles in many constitutive biological processes in addition to drug metabolism, and in this case our results are more likely to implicate this enzyme in endogenous fatty acid metabolism rather than xenobiotic metabolism.

\section{Identification of novel genes induced in an early response to food deprivation}

C. elegans has been established in the literature as a model for the investigation of fat metabolism and obesity [20,21]. Whilst there is a huge amount of information regarding the medium and long term effects of food withdrawal on C. elegans and the induction of the dauer stage, little is known about the response of the worm to 
A

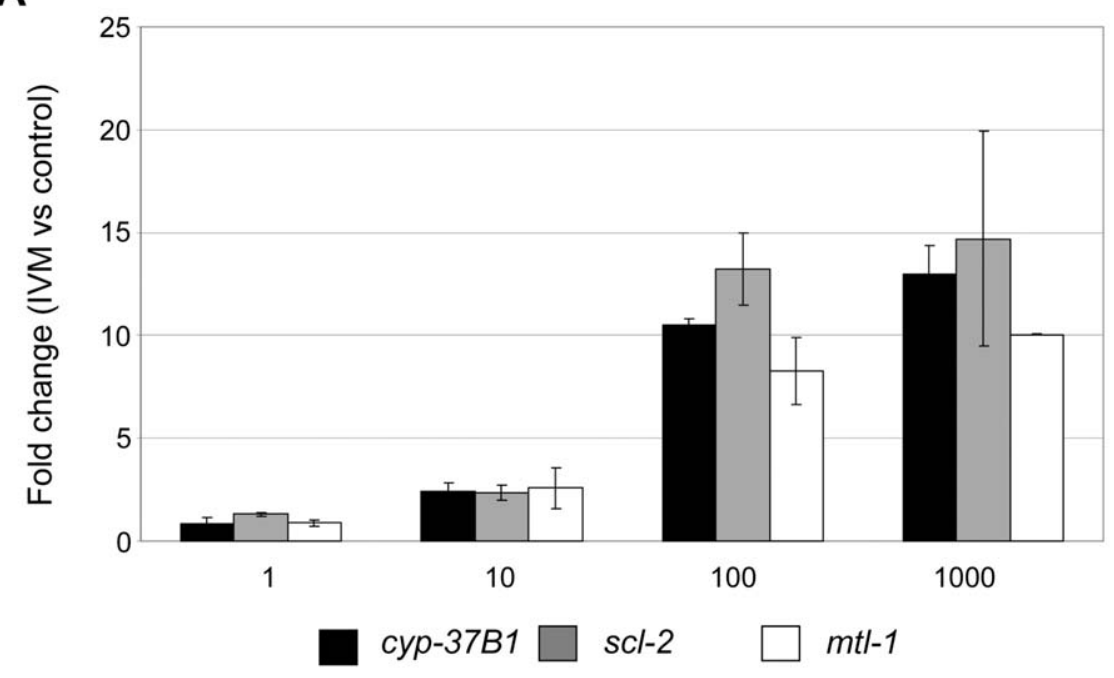

Ivermectin concentration ( $\mathrm{ng} / \mathrm{ml})$

B

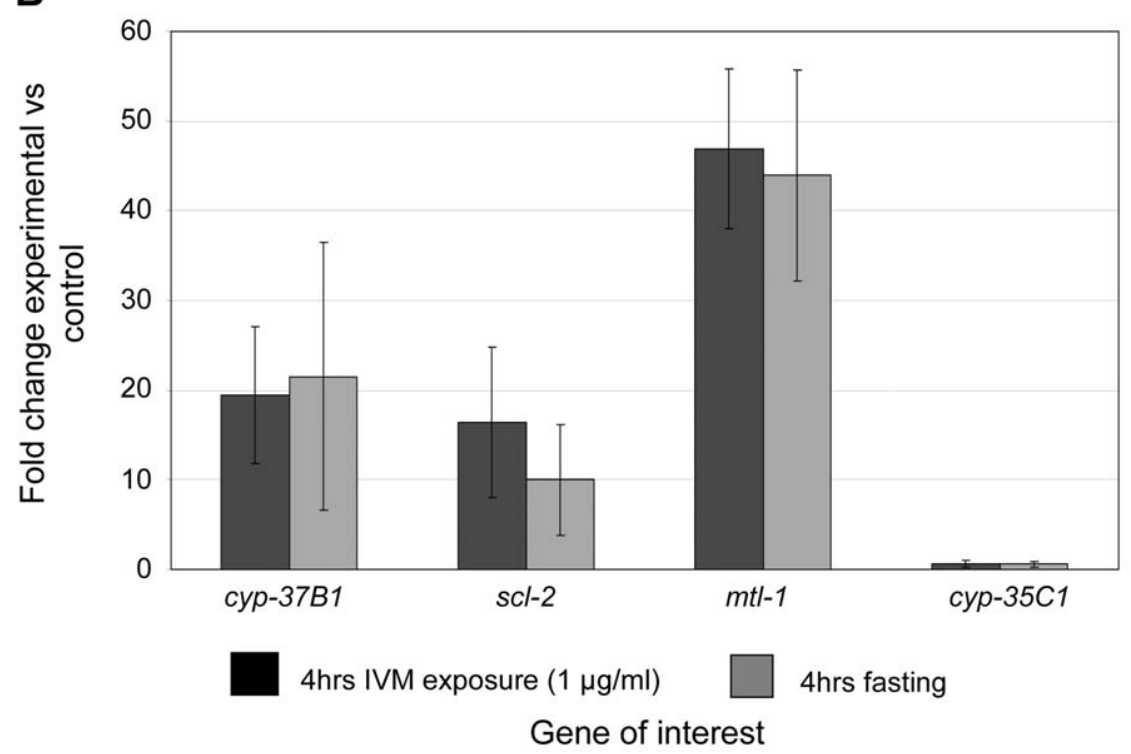

Figure 5. Up-regulation of $c y p-37 B 1, m t /-1$ and $s c l-2$ in response to varying concentrations of IVM and fasting. A. Up-regulation of the genes of interest appears to occur in a dose-dependent manner. Biological replicates were carried out in duplicate and the error bars represent the standard error. B. There are no significant differences in the fold up-regulation of the genes investigated following exposure to $1 \mu \mathrm{g} / \mathrm{ml}(1.1 \mu \mathrm{M})$ IVM and $4 \mathrm{hr}$ fasting. cyp-35C1 (a gene transcriptionally induced by benzimidazole drug exposure [18]), included as a control, was unaffected by either treatment.

doi:10.1371/journal.pone.0031367.g005

the earliest effects of food withdrawal. The identification of genes that are induced by short-term food deprivation was an unanticipated result of this study that is nevertheless potentially important. We have confirmed three of the genes $(m t l-1, c y p-37 B 1$ and $s c l-2)$ induced by IVM exposure are truly induced by food withdrawal. Many of the other induced genes, most of which have not been ascribed a functional annotation, are likely to also be novel early fasting response/fat metabolism genes. An investigation of this and their role in these processes will be an interesting area of future study and may be relevant to fat mobilization and the molecular response to food deprivation in mammals.

$m t l-1, c y p-37 B 1$ and $s c l-2$ have not been previously implicated in fasting responses or fat metabolism in $C$. elegans and so it is interesting to speculate on their roles in these processes. $m t l-1$ is a metallothionein gene, which is inducible in response to heavy metal intoxication and stress adaptation [40]. Both rat and mouse $m t l$ genes have been shown to be induced following fasting and may act as an antioxidant in the mouse [45-47]. However, metallothioneins have also been proposed to be involved in zinc signalling pathways within mammalian cells [48]. The C. elegans $m t l-1$ gene is significantly divergent from the mammalian genes. In fact, Ce-mtl-1 is the largest known metallothionein gene thus far investigated and therefore the function of MTL-1 may also be divergent in this species [40]. Interestingly, $m t l-1$ has been noted to be up-regulated in response to several xenobiotics including progesterone, clofibrate and $\beta$-naphthoflavone and was also up- 


\begin{tabular}{|c|c|c|c|c|}
\hline Gene ID & Gene Name & Type of reporter & GFP expression & Image \\
\hline K11G9.6 & $m t l-1$ & $\begin{array}{l}\text { PCR-fusion } \\
\text { (transcriptional) }\end{array}$ & $\begin{array}{l}\text { intestine and terminal } \\
\text { bulb of pharynx }\end{array}$ & \\
\hline F49E11.10 & $s c l-2$ & $\begin{array}{l}\text { PCR-fusion } \\
\text { (transcriptional) }\end{array}$ & intestine & \\
\hline C23G10.11 & uncharacterised & $\begin{array}{l}\text { PCR-fusion } \\
\text { (transcriptional) }\end{array}$ & $\begin{array}{l}\text { hypodermis (dorsal and } \\
\text { ventral) }\end{array}$ & \\
\hline F28G4.1 & cyp-37BI & $\begin{array}{l}\text { PCR-fusion } \\
\text { (transcriptional) AND } \\
\text { plasmid PJM-355 } \\
\text { (transcriptional) }\end{array}$ & intestine & \\
\hline C45G7.3 & ilys -3 & $\begin{array}{l}\text { PCR-fusion } \\
\text { (transcriptional) }\end{array}$ & $\begin{array}{l}\text { anterior intestine } \\
\text { (weak) }\end{array}$ & \\
\hline
\end{tabular}

Figure 6. GFP expression patterns of IVM responsive genes. $m t \mid-1$, scl-2, cyp-37B1 and ilys-3 are expressed in the intestine and C23G10.11 is expressed in the hypodermal cells. These are both proposed sites of fat storage. doi:10.1371/journal.pone.0031367.g006

regulated in nematodes grown in axenic culture [36,38,49]. The phenotype of worms exposed to these xenobiotics was not reported in the literature. However, it seems likely that induction of $m t l-1$ occurs under many different circumstances and may represent part of a common signalling pathway rather than an effector protein in the response to xenobiotic intoxication or food withdrawal.

The mtl-1 transcriptional GFP reporter construct showed constitutive expression in the intestine. Previous reported studies have suggested that whilst $m t l-1$ can be induced in the gut, constitutive expression is only found in the posterior bulb of the pharynx [41]. This would also suggest that $m t l-1$ expression is higher in strain DA1316 than wild-type worms. The reason for this may be due to a level of pharyngeal dysfunction noted in glutamate-gated chloride channel subunit mutants, also noted in the slightly lower resting pharyngeal pumping rate of this strain (Figure 1) [10]. Hypothetically, this could result in slightly decreased food intake and a chronic up-regulation of the pathways involved in this response.

There have been no citations for $s c l-2$ in the literature and its function remains largely unknown. However, the gene encodes a sterol carrier-like protein domain and may potentially be involved in the transport of steroid hormones or lipid breakdown products. Up-regulation of a gene involved in such processes during food deprivation would be expected. Expression of $s c l-2$ appears to be confined to the intestinal cells at all stages. The intestinal cells represent a major site of fat storage in the nematodes [39]. Therefore, the localised expression of $s c l-2$ in the intestine makes it ideally placed for involvement in fat mobilization.
cyp-37B1 represents a cytochrome $\mathrm{P} 450$ gene which encodes a CYP4/CYP19/CYP26 domain. Again, this gene has been shown to be up-regulated in response to other xenobiotics, but the phenotype of the exposed worms was not reported [36-38]. BLASTp analysis reveals that isoform 1 of CYP4V2 is a homologue of C. elegans CYP37B1 in the Homo sapiens genome (BLAST E-value $7.9 \times 10^{-98}, 90.6 \%$ length). Mutations of the gene encoding CYP4V2 have been associated with Bietti Crystalline Corneoretinal Dystrophy and the protein has recently been characterised as a fatty acid \{omega\}-hydroxylase [50,51]. cyp$37 B 1(R N A i)$ suggests that this gene may have limited hydroxylase activity against eicosapentaenoic acid in C. elegans [52]. Therefore, it is possible that this cytochrome P450 is also involved in fat mobilisation in response to food deprivation. The expression of this gene in the intestine of the nematodes corroborates this hypothesis. However, there was also expression in the phasmid neurons, which may suggest involvement in chemosensation. Certainly, C. elegans appear to be able to sense IVM in their environment. Both wild-type (N2) and DA1316 animals will attempt to migrate off IVM containing NGM plates at concentrations of drug not high enough to cause immediate paralysis (data not shown).

Our initial hypothesis, that exposure of C. elegans to IVM would result in the up-regulation of xenobiotic metabolising enzymes, has been largely disproved in the current study. However, the pharyngeal dysfunction and associated decreased food intake caused by IVM, even in a highly resistant strain such as DA1316, has resulted in the identification of genes not previously implicated in food deprivation. Further investigation into the function of these 
genes should provide insight into the molecular pathways involved in reduced food intake, fasting and fat mobilization, both in nematodes and in higher species. Additionally, the recognition that IVM still induces a degree of pharyngeal paralysis in a mutant carrying null mutations in three glutamate-gated chloride channel subunits (avr-14, avr-15 and glc-1) suggests the existence of additional targets of the drug that are involved in nematode pharyngeal function.

\section{Supporting Information}

Table S1 Primer sets for real-time QPGR and GFPfusion constructs.

(XLS)

Table S2 Complete list of genes with significant changes in expression following IVM exposure. Log fold change in expression of all genes with a false discovery rate of less than $5 \%$ in both the $100 \mathrm{ng} / \mathrm{ml}(0.1 \mu \mathrm{M})$ and $1 \mu \mathrm{g} / \mathrm{ml}(1.1 \mu \mathrm{M})$ IVM experiments are listed.

(XLS)

\section{References}

1. Fox LM (2006) Ivermectin: uses and impact 20 years on. Curr Opin Infect Dis 19: 588-593. 10.1097/OCO.0b013e328010774c [doi];00001432-20061200000011 [pii].

2. Gilleard JS (2006) Understanding anthelmintic resistance: the need for genomics and genetics. Int J Parasitol 36: 1227-1239.

3. Edward CL, Hoffmann AA (2008) Ivermectin resistance in a horse in Australia. Vet Rec 162: 56-57. 162/2/56 [pii].

4. Kaplan RM (2004) Drug resistance in nematodes of veterinary importance: a status report. Trends Parasitol 20: 477-481.

5. Sargison ND, Jackson F, Bartley DJ, Wilson DJ, Stenhouse LJ, et al. (2007) Observations on the emergence of multiple anthelmintic resistance in sheep flocks in the south-east of Scotland. Vet Parasitol 145: 65-76. S03044017(06)00621-2 [pii];10.1016/j.vetpar.2006.10.024 [doi].

6. Awadzi K, Boakye DA, Edwards G, Opoku NO, Attah SK, et al. (2004) An investigation of persistent microfilaridermias despite multiple treatments with ivermectin, in two onchocerciasis-endemic foci in Ghana. Ann Trop Med Parasitol 98: 231-249. 10.1179/000349804225003253 [doi].

7. Churcher TS, Pion SD, Osei-Atweneboana MY, Prichard RK, Awadzi K, et al. (2009) Identifying sub-optimal responses to ivermectin in the treatment of River Blindness. Proc Natl Acad Sci U S A 106: 16716-16721. 0906176106 [pii];10.1073/pnas.0906176106 [doi].

8. Osei-Atweneboana MY, Eng JK, Boakye DA, Gyapong JO, Prichard RK (2007) Prevalence and intensity of Onchocerca volvulus infection and efficacy of ivermectin in endemic communities in Ghana: a two-phase epidemiological study. Lancet 369: 2021-2029. S0140-6736(07)60942-8 [pii];10.1016/S01406736(07)60942-8 [doi].

9. Dent JA, Davis MW, Avery L (1997) avr-15 encodes a chloride channel subunit that mediates inhibitory glutamatergic neurotransmission and ivermectin sensitivity in Caenorhabditis elegans. EMBO J 16: 5867-5879. 10.1093/ emboj/16.19.5867 [doi].

10. Dent JA, Smith MM, Vassilatis DK, Avery L (2000) The genetics of ivermectin resistance in Caenorhabditis elegans. Proc Natl Acad Sci U S A 97: 2674-2679.

11. Etter A, Cully DF, Schaeffer JM, Liu KK, Arena JP (1996) An amino acid substitution in the pore region of a glutamate-gated chloride channel enables the coupling of ligand binding to channel gating. J Biol Chem 271: 16035-16039.

12. Pemberton DJ, Franks CJ, Walker RJ, Holden-Dye L (2001) Characterization of glutamate-gated chloride channels in the pharynx of wild-type and mutant Caenorhabditis elegans delineates the role of the subunit GluCl-alpha2 in the function of the native receptor. Mol Pharmacol 59: 1037-1043.

13. Vassilatis DK, Arena JP, Plasterk RH, Wilkinson HA, Schaeffer JM, et al. (1997) Genetic and biochemical evidence for a novel avermectin-sensitive chloride channel in Caenorhabditis elegans. Isolation and characterization. J Biol Chem 272: 33167-33174.

14. Yates DM, Portillo V, Wolstenholme AJ (2003) The avermectin receptors of Haemonchus contortus and Caenorhabditis elegans. Int J Parasitol 33: 1183-1193.

15. Holden-Dye L, Walker RJ (2006) Actions of glutamate and ivermectin on the pharyngeal muscle of Ascaridia galli: a comparative study with Caenorhabditis elegans. Int J Parasitol 36: 395-402.

16. Brownlee DJ, Holden-Dye L, Walker RJ (1997) Actions of the anthelmintic ivermectin on the pharyngeal muscle of the parasitic nematode, Ascaris suum. Parasitology 115(Pt 5): 553-561

17. McCavera S, Rogers AT, Yates DM, Woods DJ, Wolstenholme AJ (2009) An ivermectin-sensitive glutamate-gated chloride channel from the parasitic
Table S3 Ontology terms associated with up-regulated genes in response to exposure of DA1316 to $1 \mu \mathrm{g} / \mathrm{ml}$ $(1.1 \mu M)$ IVM for $4 \mathrm{hr}$.

(XLSX)

Table S4 Ontology terms associated with down-regulated genes in response to exposure of DA1316 to $1 \mu \mathrm{g} /$ ml $(1.1 \mu M)$ IVM for $4 \mathrm{hr}$.

(XLSX)

Table S5 Log fold change in expression of "classic" stress response genes following IVM exposure $(1 \mu \mathrm{g} / \mathrm{ml}$, $1.1 \mu \mathbf{M})$.

(XLS)

\section{Author Contributions}

Conceived and designed the experiments: SL JG. Performed the experiments: SL VB SR. Analyzed the data: SL AI RL JG. Wrote the paper: SL. Drug experiments: SL. RNA methods: SL. RT-QPCR: SL. Microarray hybridization and normalization: AI. GFP reporters: SL VB SR. Supervision and critical reading of the manuscript: DW JG.

nematode Haemonchus contortus. Mol Pharmacol 75: 1347-1355. mol.108.053363 [pii];10.1124/mol.108.053363 [doi].

18. Laing ST, Ivens A, Laing R, Ravikumar S, Butler V, et al. (2010) Characterization of the xenobiotic response of Caenorhabditis elegans to the anthelmintic drug albendazole and the identification of novel drug glucoside metabolites. Biochem J 432: 505-514. BJ20101346 [pii];10.1042/BJ20101346 [doi].

19. Gonzalez CA, Sahagun Prieto AM, Jose Diez LM, Martinez NF, Vega MS, et al. (2009) The pharmacokinetics and metabolism of ivermectin in domestic animal species. Vet J 179: 25-37. S1090-0233(07)00249-3 [pii];10.1016/ j.tvjl.2007.07.011 [doi].

20. Jones KT, Ashrafi K (2009) Caenorhabditis elegans as an emerging model for studying the basic biology of obesity. Dis Model Mech 2: 224-229. 2/5-6/224 [pii];10.1242/dmm.001933 [doi].

21. Zheng J, Greenway FL (2011) Caenorhabditis elegans as a model for obesity research. Int J Obes (Lond). ijo201193 [pii];10.1038/ijo.2011.93 [doi].

22. Jeong PY, Kwon MS, Joo HJ, Paik YK (2009) Molecular time-course and the metabolic basis of entry into dauer in Caenorhabditis elegans. PLoS One 4: e4162. 10.1371/journal.pone.0004162 [doi].

23. Wang J, Kim SK (2003) Global analysis of dauer gene expression in Caenorhabditis elegans. Development 130: 1621-1634.

24. Van Gilst MR, Hadjivassiliou H, Yamamoto KR (2005) A Caenorhabditis elegans nutrient response system partially dependent on nuclear receptor NHR49. Proc Natl Acad Sci U S A 102: 13496-13501.

25. Stiernagle T (1999) Maintenance of C. elegans. In: Hope IA, ed. C. elegans A Practical Approach. Oxford: Oxford University Press. pp 51-67.

26. Johnstone IA (1999) Molecular Biology. In: Hope IA, ed. C. elegans A Practical Approach Oxford University Press. pp 201-225.

27. Breitling R, Armengaud P, Amtmann A, Herzyk P (2004) Rank products: a simple, yet powerful, new method to detect differentially regulated genes in replicated microarray experiments. FEBS Lett 573: 83-92. 10.1016/j.febslet.2004.07.055 [doi];S0014579304009354 [pii].

28. Dennis G Jr., Sherman BT, Hosack DA, Yang J, Gao W, et al. (2003) DAVID Database for Annotation, Visualization, and Integrated Discovery. Genome Biol 4: 3 .

29. Huang DW, Sherman BT, Lempicki RA (2009) Systematic and integrative analysis of large gene lists using DAVID bioinformatics resources. Nat Protoc 4: 44-57. nprot.2008.211 [pii];10.1038/nprot.2008.211 [doi].

30. Jonstone IL, Barry JD (1996) Temporal reiteration if a precise gene expression pattern during nematode development. EMBO J 15: 3633-3639.

31. Hobert $\mathrm{O}$ (2002) PCR fusion-based approach to create reporter gene constructs for expression analysis in transgenic C. elegans. Biotechniques 32: 728-730.

32. Fire A, Harrison SW, Dixon D (1990) A modular set of lacZ fusion vectors for studying gene expression in Caenorhabditis elegans. Gene 93: 189-198.

33. Mello CC, Kramer JM, Stinchcomb D, Ambros V (1991) Efficient gene transfer in C.elegans: extrachromosomal maintenance and integration of transforming sequences. EMBO J 10: 3959-3970.

34. Kimura KD, Tissenbaum HA, Liu Y, Ruvkun G (1997) daf-2, an insulin receptor-like gene that regulates longevity and diapause in Caenorhabditis elegans. Science 277: 942-946.

35. James CE, Davey MW (2009) Increased expression of ABC transport proteins is associated with ivermectin resistance in the model nematode Caenorhabditis elegans. Int J Parasitol 39(2): 213-20. 
36. Custodia N, Won SJ, Novillo A, Wieland M, Li C, et al. (2001) Caenorhabditis elegans as an environmental monitor using DNA microarray analysis. Ann N Y Acad Sci 948: 32-42.

37. Menzel R, Yeo HL, Rienau S, Li S, Steinberg CE, et al. (2007) Cytochrome $\mathrm{P} 450 \mathrm{~s}$ and short-chain dehydrogenases mediate the toxicogenomic response of PCB52 in the nematode Caenorhabditis elegans. J Mol Biol 370: 1-13.

38. Reichert K, Menzel R (2005) Expression profiling of five different xenobiotics using a Caenorhabditis elegans whole genome microarray. Chemosphere 61: 229-237.

39. Mullaney BC, Ashrafi K (2009) C. elegans fat storage and metabolic regulation. Biochim Biophys Acta 1791: 474-478. S1388-1981(08)00241-2 [pii];10.1016/ j.bbalip.2008.12.013 [doi].

40. Cui Y, McBride SJ, Boyd WA, Alper S, Freedman JH (2007) Toxicogenomic analysis of Caenorhabditis elegans reveals novel genes and pathways involved in the resistance to cadmium toxicity. Genome Biol 8: R122.

41. Freedman JH, Slice LW, Dixon D, Fire A, Rubin CS (1993) The novel metallothionein genes of Caenorhabditis elegans. Structural organization and inducible, cell-specific expression. J Biol Chem 268: 2554-2564.

42. Bargmann CI (2006) Chemosensation in C. elegans. WormBook. pp 1-29. 10.1895/wormbook.1.123.1 [doi].

43. Ashrafi K (2007) Obesity and the regulation of fat metabolism. WormBook. pp 1-20. 10.1895/wormbook.1.130.1 [doi].

44. Ardelli BF, Stitt LE, Tompkins JB, Prichard RK (2009) A comparison of the effects of ivermectin and moxidectin on the nematode Caenorhabditis elegans. Vet Parasitol;S0304-4017(09)00379-3 [pii];10.1016/j.vetpar.2009.06.043 [doi].

45. Kondoh M, Kamada K, Kuronaga M, Higashimoto M, Takiguchi M, et al. (2003) Antioxidant property of metallothionein in fasted mice. Toxicol Lett 143: 301-306. S0378427403001954 [pii].
46. Shinogi M, Sakaridani M, Yokoyama I (1999) Metallothionein induction in rat liver by dietary restriction or exercise and reduction of exercise-induced hepatic lipid peroxidation. Biol Pharm Bull 22: 132-136.

47. Sogawa N, Sogawa CA, Fukuoka H, Mukubo Y, Yoneyama T, et al. (2003) The changes of hepatic metallothionein synthesis and the hepatic damage induced by starvation in mice. Methods Find Exp Clin Pharmacol 25: 601-606. 778079 [pii].

48. Cousins RJ, Liuzzi JP, Lichten LA (2006) Mammalian zinc transport, trafficking, and signals. J Biol Chem 281: 24085-24089. R600011200 [pii];10.1074/ jbc.R600011200 [doi].

49. Szewczyk NJ, Udranszky IA, Kozak E, Sunga J, Kim SK, et al. (2006) Delayed development and lifespan extension as features of metabolic lifestyle alteration in C. elegans under dietary restriction. J Exp Biol 209: 4129-4139. 209/20/4129 [pii];10.1242/jeb.02492 [doi].

50. Li A, Jiao X, Munier FL, Schorderet DF, Yao W, et al. (2004) Bietti crystalline corneoretinal dystrophy is caused by mutations in the novel gene CYP4V2. Am J Hum Genet 74: 817-826. 10.1086/383228 [doi];S0002-9297(07)64351-1 [pii].

51. Nakano M, Kelly EJ, Rettie AE (2009) Expression and Characterization of CYP4V2 as a Fatty Acid \{omega\}-Hydroxylase. Drug Metab Dispos;dmd.109.028530 [pii];10.1124/dmd.109.028530 [doi].

52. Kulas J, Schmidt C, Rothe M, Menzel R (2008) Cytochrome P450-dependent metabolism of eicosapentaenoic acid in the nematode Caenorhabditis elegans. Arch Biochem Biophys 472(1): 65-75. 